
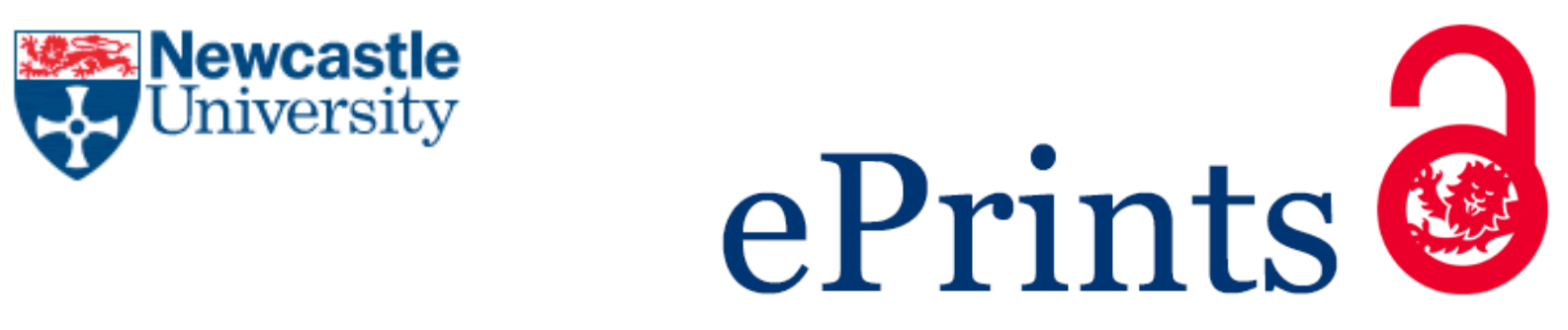

Mearns GW, Richardson R, Robson E.

Enacting the internet and social media on the public sector's frontline. New Technology, Work and Employment 2015, 30(3), 190-208.

\title{
Copyright:
}

This is the peer reviewed version of the above article, which has been published in final form at http://dx.doi.org/10.1111/ntwe.12054. This article may be used for non-commercial purposes in accordance with Wiley Terms and Conditions for Self-Archiving.

Date deposited:

$15 / 03 / 2016$

Embargo release date:

09 December 2017 


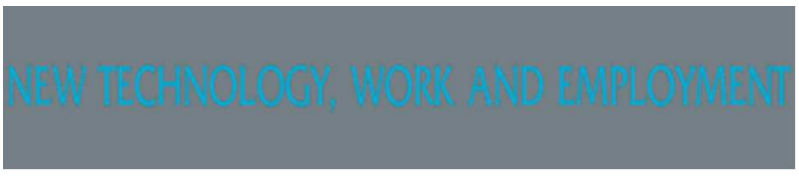

\section{Enacting the internet and social media on the public sector's frontline.}

\begin{tabular}{|c|l|}
\hline Journal: & New Technology, Work and Employment \\
\hline Manuscript ID & MA-NTWE-Dec-2014-071.R4 \\
\hline Weywords: $:$ & $\begin{array}{l}\text { ICTs, social media, street-level bureaucrats, organisational change, youth } \\
\text { sector, enactment }\end{array}$ \\
\hline Abstract: & $\begin{array}{l}\text { Recognising their growing role in public services, this article draws on } \\
\text { Fountain's (2001) notion of 'enactment' to argue that the internet and } \\
\text { social media (I\&SM) need to be understood in particular institutional and } \\
\text { organisational frames. Focusing on street-level bureaucrats who deliver } \\
\text { frontline services, we explore efforts to integrate I\&SM into youth work } \\
\text { with clients who are thought to be 'digitally savvy' but also in need of } \\
\text { protection from the 'online world'. As clients can be vulnerable and trust is } \\
\text { complex and under continuous renegotiation. However, the layering of new } \\
\text { virtual channels of interaction adds extra complexity. This necessitates the } \\
\text { development of innovative routines, practices and protocols but these are } \\
\text { being developed in a wider social context where the norms of using social } \\
\text { media have not caught up with practice and the use of these tools is still } \\
\text { often surrounded by moral panic. }\end{array}$ \\
\hline
\end{tabular}




\title{
Enacting the internet and social media on the public sector's frontline.
}

\begin{abstract}
Recognising their growing role in public services, this article draws on the notion of 'enactment' to argue that the internet and social media (I\&SM) need to be understood in particular institutional, organisational and social contexts. Focusing on street-level bureaucrats who deliver frontline services, we explore efforts to integrate I\&SM into youth work with clients who are thought to be 'digitally savvy' but also in need of protection from the 'online world'. As clients can be vulnerable and trust is a key relational component, organisation-practitioner-client boundaries are complex and under continuous renegotiation. However, the layering of new virtual channels of interaction adds extra complexity. This change necessitates the development of innovative routines, practices and protocols but these are being developed in a wider social context where the norms of using social media have not caught up with practice and the use of these tools is still often surrounded by moral panic.
\end{abstract}

\section{Keywords}

ICTs, social media, street-level bureaucrats, e-government, youth sector 


\section{This rise of e-government and e-public services}

The terms 'e-government' (Silcock, 2001) and 'digital era governance' (Dunleavy et al., 2006) describe the penetration of information and communication technologies (ICTs) into all aspects of public service organisation at both national and local levels. The e-government trend is well established in advanced economies and is growing elsewhere (Heeks and Bailur, 2006; Punie, et al., 2009; United Nations, 2014). In the UK, successive governments have tried to embed ICTs across the public sector. As part of their modernisation agenda, the Blair-Brown Labour administrations (1997-2010) sought to create e-enabled transformational government (Cabinet Office, 2005). These initiatives strove to join up what was considered to be a fragmented public service environment to create citizen centric services (Baines et al., 2010). In the latter years of the Labour governments, the focus moved from internal systems towards 'transactional services' (Margetts, 2009)._This transition mirrored what was happening in the private sector.

From 2010, the Conservative-Liberal Coalition started to accelerate electronic interaction with the public. Drawing on a 'digital by default' mantra, it set targets for central government to 'deliver better for less' through online services. The Government Digital Service (GDS) was launched to coordinate this activity. To translate digital by default principles and promote transactional services locally, the Coalition established a central-local partnership led by the Department for Community and Local Government (DCLG) named Digital Local. Local public service delivery is fragmented and many other organisations like the Local Government Innovation Unit (LGiU), Local Government Association (LGA), Society of Information Technology Management (Socitim), National Health Service (NHS), Quality Care (QC) and Race Online have championed the digitisation of services in both public and third sectors. 
The mid-2000s had seen growing recognition of the need to move beyond e-enabling transactional services to integrate services within organisations and frontline interactions (see, for example, Baines et al., 2010; Carter et al. 2011). The growth in the use of the internet and social media (I\&SM) has placed additional emphasis on the need to make this transition. Surveys suggest that the integration of I\&SM in local services has been gathering_pace and is expected to increase in coming years (Denham, 2013). It is thought that utilising these technologies will deliver improved and more cost effective local public services that can reshape the relationships between agencies and their client bases (Carr-West et al., 2009; Chadwick, 2009; Ellison and Hardey, 2013; Gibson, 2010; Thornton, 2014). More public and third sector workers are now regularly interacting with - and through - ICTs in the workplace.

This article is concerned with the adoption of I\&SM by Street Level Bureaucrats (SLB) (Lipsky, 1980; 2010), frontline professionals in bureaucracies who deliver welfare and social services to clients. Burton and van der Broek (2009) explain how ICTs are being used to shape relationships between SLB and the bureaucracies within which they operate. Similarly, Baines et al. (2010) describe the deployment of ICTs as part of efforts to overcome professional and organisational silos in public service delivery. Increasingly, ICTs are also being integrated into the SLB practitioner-client interface in services such as health care (Hawn, 2009), social care (Ayres, 2013), social housing (Richardson and Abbott, 2013) and social work (Kimball and Kim, 2013). This article's focus is on how I\&SM are integrated into youth work, where policymakers, practitioners and digital evangelists have high expectations of the utility of these tools (Davies and Cranston, 2008; HM Government, 2011). These expectations are based on several factors. First, young people tend to be early adopters and heavy users of tools like Facebook and YouTube and are thought to have a particular affinity with them (Tapscott, 2009). Second, I\&SM are deemed a key means through which young people's interests, relationships and learning 
can be widened, bolstered and shared. There is much emphasis on new curative and creative practices and on engaging 'actively' as citizens (Aydin, 2012; Ellison et al., 2011; Livingstone et al., 2005; Loader, 2007; Metcalf et al., 2008). This emphasis is particularly salient as engagement, participation and empowerment are central to youth work (Davies, 2010). Thirdly, despite their superior technological familiarity, young people, it is assumed, need guidance in navigating the online world safely. The supposition is that youth workers can play a role, particularly in hard to reach geographical contexts with disenfranchised young people (HM Government, 2011).

Despite the trend towards I\&SM in local public services, the speed of adoption is widely criticised, as is the slow pace of service innovation which is described as lagging the commercial sector and failing to meet citizens' expectations (Denham, 2013; Slee, 2014). This article draws on the notion of 'enactment' to develop a fuller understanding of the complex processes which may facilitate or retard the adoption of technologies in this context and which, respectively, may support or undermine policy intentions. Enactment is understood in different ways although most commentators eschew technologically-determinist approaches._For example, Fountain (2001) uses the term to mean that the 'outcomes of the application of [ICTs] are mediated by contextual, institutional and organisational conditions which influence choices and decisions about the deployment and use of technology in particular contexts' (Baines et al., 2010: 21). The distinction between institutional and organisational conditions is important in the context of the current article, as the former refers to the norms, values and practices in wider society and suggests that organisations will to some extent be circumscribed by these conditions.

However, for some, Fountain's 'neo-institutional' approach over-emphasises the tendency for individual enactment of technologies to reproduce existing power relations and 
does not pay enough attention to individual agency for change. One such critic, Kaifeng Yang, suggests that a 'constructivist view' could enrich Fountain's framework by showing that 'technology is not only perceived and used differently in organisations but also further shaped and innovated because of different social perceptions (Yang 2003: 435). Orlikowski (1992, 2000) also drawing on constructivist traditions, seeks to develop a 'structurational' perspective on technology which is 'inherently dynamic and grounded in on-going human action' (2000: 405). Orlikowski (1992) introduces an analytical distinction between 'design mode' and 'use mode' of human technology interactions, later elaborating this distinction by referring to technology as artefact which has certain 'designed-in' properties and uses of technology in everyday life. She suggests that a practice-oriented perspective is required to better account for emergence and change in both technologies and their use in organisations. In this reading, there is an important balance between 'materiality' of technology and on 'what structures emerge as people interact recurrently with whatever properties of the technology are at hand, whether these were built in, added on, modified, or invented on the fly' (Orlikowski, 2000: 407). In a world where technologies are increasingly reconfigurable, the room for individual or collective repurposing of technologies becomes ever greater, albeit not open-ended.

In more recent writing, Orlikowski (2007) and Scott and Orlikowski (2014) adopt a 'sociomaterial analysis'. In so far as this represents a more sophisticated iteration of the design mode-use mode argument, it seeks to challenge technological duality and we find this a useful contribution. However, the notion of 'constitutive entanglement' is more problematic. It has value in drawing attention to deep interdependencies at the structural level but it shares the difficulty of many post-humanist and other approaches that seek to adapt metaphors from non-social science disciplines. In particular, it has limited application to the sort of case study methods employed in organisational studies. So, 'pre-existing categories' are questioned in constructing 
the constitutive entanglement conceptual framework, but are implicitly or explicitly reintroduced in the illustrative case studies. Scott and Orlikowski's (2014) analysis of the 'travel sector is a good example of this tendency.

This article concentrates on how I\&SM play out in the context of SLB in delivering frontline public services which have a strong relational component. Particular attention is paid to youth work. Empirically, the extent to which I\&SM Is being adopted by youth workers is examined, considering the challenges of integrating these technologies and developing innovative practices around them, whilst also reflecting on their meaning for managers and frontline workers. Although intra-organisational developments are considered, the key contribution of the article is to explore the space between the organisation and client and the way that I\&SM are enacted in these spaces. We draw on Fountain's work on organisational change whose strength, it is argued, is two-fold. First, it pays attention to what is called 'programmatic intentionality', by which we mean that there are a set of actors who seek particular outcomes from technological investment. Second, and relatedly, it recognises the importance of the small ' $p$ ' politics in accommodating, progressing or resisting this intentionality. However, the argument also draws on Orlikowski's 'practice lens' approach to add richness in terms of understanding the emergence and the complexity of human-technology relationships.

Following an overview of the relevant literature, the article describes the methods used in the study. The research findings are then presented in two parts for analytical purposes. The first considers the intra-organisational challenges faced by frontline agencies and workers. The second is concerned more with the potential impact of I\&SM at the practitioner-client interface, explaining the ways in which new 'virtual' relational spaces are emerging, how workers operate in and manage these spaces, and what this means for work practices and routines. The article 
concludes with discussion of what these processes might mean for frontline public service work more generally.

\section{Enrolling I\&SM into public services}

Critical researchers are only beginning to address the extent of adoption of the most recent wave of new technologies in public services and what the implications might be for work processes and organisational change. However, emerging policy and practice literature suggest a number of factors inhibiting rapid innovation around I\&SM. Resource constraints are the first (DCLG, 2013). As a result of the current austerity regime in the UK, council budgets have sustained annual cost cuts since 2010, a process expected to continue until at least 2020 . Worker head counts have fallen, with one in six posts lost between 2010-13 (Pickard, 2014). This contraction has had a knock on effect on voluntary organisations which have tended to rely on local authorities for parts of their funding (National Council of Voluntary Organisations, 2014).

A second factor is the cost of new technologies which is exacerbated by funding cuts. In terms of capital, social media do not necessarily involve the scale of investment associated with previous rounds of ICT. However, it 'is not cost free' (Nah and Saxton, 2013: 298). Integrating new rounds of technology with existing legacy systems is a problem (Batlajery et al., 2014; Laffin and Ormston, 2013). The legacy system problem is aggravated by the wide range of I\&SM platforms adopted by users and high turnover in the popularity of platforms among internet users. This development is especially true for younger people (Lenhart, et al., 2010). Mobile applications and the emergence of image-based applications like Instagram and 
Snapchat add further complexity. A survey suggested local authorities faced a threefold increase in the number of platforms that they needed to service between 2012-13 (Slee, 2014).

System integrity and security is a third factor, as formerly 'closed' systems become linked with external platforms and applications used by both staff and the public. One reported trend is for workers to use their own personal technologies for work, referred to as 'bring your own device' (BYOD). BYOD puts sensitive information at risk, as personal data can be transferred between insecure devices (Morrow, 2012; Thomson, 2012). Additionally, cloud storage providers like Dropbox are often used by staff to bypass unwieldy corporate systems. Again, this usage is mainly attributable to younger workers, suggesting that age-related differences in I\&SM practices in the social sphere, such as those reported by Lenhart et al. (2010), might be spilling over into the workplace. The use of non-work technologies is reported mainly in relation to private sector knowledge workers but is also apparent in frontline public service work (Abbott and Richardson, 2013). An increasing number of people first experience new technologies outside work where they develop personal navigation routines more effective than those designed around 'clunky' office-ware (Wallace, 2014).

A fourth reported factor is the paucity of leadership and vision from senior managers and politicians at the local level. By 2013, just one third of UK councils had created a digital strategy (DCLG, 2013). This factor is noteworthy given the significant policy and financial investment made in digital government throughout the 2000 s. Another survey, focusing explicitly on frontline services, showed that only a quarter of local authority organisations were using social media in youth and/or social work contexts (Dale, 2012). A lack of awareness and experience of social media, together with insufficient, spare management capacity (especially time) and unclear lines of digital leadership are among the factors said to be behind the slow pace of adoption. 
A fifth factor is a perceived skills deficit. Beresford (2014: 36) suggests that many frontline staff continue to have 'difficulty in using social media'. Youth practitioners have been particularly criticised for poor awareness and as lacking the technical skills needed to exploit social media (Ali and Davies, 2009; Davies and Cranston, 2008; Gibson et al., 2010). One government report warned of a widening gap between young people and youth workers (HM Government, 2011). Such claims of a continued digital skills deficit are surprising given the ubiquity of technology both in the workplace and in society generally, with the majority of working age adults now using I\&SM daily (Office of National Statistics, 2014).

Finally, risk aversion is a major factor behind the slow pace at which I\&SM are being adopted. Beresford (2014) writes of a 'generalised fear' amongst some staff. At the management level, it is reflected in a reluctance to share responsibility for digital strategy, with junior staff often being more knowledgeable but unable to contribute their expertise fully due to hierarchical structures. By contrast, frontline workers' concerns are said to be the result of negative perceptions about the impacts of technology on employment and job status (Silverman et al., 2013). At the client interface, 'fear of getting it wrong', is said to 'stifle many individuals and agencies from taking the first steps towards using I\&SM to engage as residents, service users, community groups and active citizens (Young Foundation, 2010: 2).

The aforementioned barriers mirror those that restricted the uptake of earlier waves of ICT in the workplace (Cornford, et al., 2003; McLoughlin and Cornford, 2006). However, an additional set of factors may be arising specifically associated with the 'intrinsic properties' of this set of 'new new technologies' (Howcroft and Taylor, 2014). More accurately, the properties purposefully designed into social media hardware and software combined with emerging social practices, may result in new sets of difficulties. Agger (2012) has coined the term 'deboundarying' to suggest that social media blur boundaries between public and private lives 
(and selves), creating new spaces in which people 'overshare'. Similarly, Rainie and Wellman (2012: 17) suggest that with mobile technologies, I\&SM lead to 'hyper-connectivity', contributing to 'new expectations and realities about the transparency, availability and privacy of people and institutions'. These authors point to the ways in which platforms like Facebook and Twitter are purposely designed to integrate rather than separate communities. They write of a creeping 'coveillance' to describe the way in which people, innocently or otherwise, watch each other and actively check for information about others' activities online. However, in these spaces of 'selfdisclosure' (Lovink, 2011), it is not always clear 'who' is sharing as individuals create 'multiple selves' or 'multiple identities' (Baym, 2010). This is particularly true of adolescents and young adults (Strom and Strom, 2009). Thus, the absence of social cues, gained through co-presence, which characterise previous rounds of electronic communication like email, are potentially compounded (Baumer, 2013). Although the language in these commentaries can tend towards the hyperbolic, they doubtless capture new and emerging tendencies which are driven by I\&SM.

These tendencies have mainly been attended to the social sphere, with the partial exception of the effects of electronically facilitated deboundarying of the work-life balance (Orlikowski, 2007; Rainie and Wellman, 2012). However, policy and practice literatures that consider the potential impacts of I\&SM on workplace relations is emerging in both commercial and public sector contexts (see, Chartered Institute of Public Relations, 2011). A number of issues are covered by these reports including recruitment practices, workplace cyberbullying, worker and union voice, the design of internet policy and promoting 'collective intelligence' to enhance competitiveness. However, the main issue is the perceived reputational risk faced by organisations via I\&SM which is related to the 'de-bounded' nature of interactions. Whilst the reputational risk associated with disgruntled customers using tools like Twitter are acknowledged, the studies focus on how to manage the risks of employees' use of social media 
to express 'inappropriate views' in or outside the workplace. This literature suggests that 'consensus on norms of behavior in [these] new social spaces is only just emerging, meaning that codification of acceptable and unacceptable practices has not yet taken place' (Broughton et al., 2010: 30). Therefore, guidance can only be provisional 'due to the rapid pace of change and development in social media and its use' (Institute of Business Ethics, 2011: 4).

A small but growing policy and practice literature also seeks to construct guidelines specifically for groups of frontline workers. Writing in the context of social work in the United States (US), Kimball and Kim (2013) and Reamer (2013) note the increased incidence of online interaction between practitioners, ranging from telephone counselling to 'cybertherapy' (see also Hawn, 2009). These authors are concerned with the construction and negotiation of 'virtual boundaries' (Kimball and Kim, 2013) and 'dual relationships' (Reamer, 2013). It is necessary to understand the particular I\&SM platform being used (open or closed, encrypted or not) as well as the protocols for privacy, confidentiality, informed consent, timing and the duration of communications. Both articles highlight conflicts and dangers in intermingling personal and professional identities online, stressing that professional ethical guidelines have not kept up with practice. In the UK, several trade unions now provide advice to frontline workers who interact closely with clients to protect themselves and those to whom they have a duty of care. This guidance covers issues such as online 'friending' (National Union of Teachers, 2014; National Association of Schoolmasters Union of Women Teachers, 2013).

\section{Youth workers as street-level bureaucrats}

In England, local authorities have a statutory 'duty to secure activities and wellbeing' for young people aged 13-18 years old which extends to 24 years for those with special educational needs (Department for Education, 2013). Traditionally, local authorities and other public bodies 
have delivered statutory activity, together with a range of non-statutory services. The private and voluntary sectors have also contributed to delivering services. Since the turn of the century, New Public Management (NPM) approaches have been adopted (Davies and Wood, 2010) in tandem with the purchaser-provider model, by which local authorities concentrate on commissioning and the private and voluntary sectors play an increased role. Rhetorically, NPM was complemented by 'big society' style localism advocated by the Conservative-Liberal Coalition which encouraged voluntary sector involvement. Consequently, a range of agencies in addition to local authorities deliver youth services, including large, national, professionalised charities like Barnados and the Prince's Trust, churches, and smaller local and communitybased voluntary groups and charity networks and partnerships. Some work exclusively with young people while others have a wider remit.

Youth work is diverse, involving professional and volunteer practitioners (Davies, 2010). Services are delivered in formal and informal settings and in structured and unstructured ways (Ali and Davies 2009). Interviewees described multiple goals including bringing young people into cultural-creative and social settings while also driving ambitious, longitudinal participation programs in formal and informal democratic processes. The work involves skills and confidence building, providing peer support and encouraging young people's interaction within and with their local communities. These processes take place in site-specific settings such as community centres, schools and youth clubs, but also through 'outreach' on the streets.

Youth workers are archetypal SLB in many respects. Much of the added value of their work emerges from client interaction. These relationships are complex with practitioners providing services to clients by entering their 'private personal physical and/or psychological space, either intensively over a short or sustained period of time' (Farvaque and Yonnet, 2007: 21). Sercombe writes of a 'covenantal relationship of "trust" between youth worker and client' 
(Sercombe, 2010: 37). However, practitioners also play a major role in managing and controlling behaviour on the path to adulthood. Davies and Merton (2009) characterise youth workers as 'friends with authority'. Like other SLB, youth workers must also meet their employer's goals, objectives, and targets. SLB organisations are not autonomous as much of their work is determined by central and local government policy and funding. This can be short-term and at odds with the ethos of an organisation or individual worker. The same is true for the voluntary sector. SLB workers must therefore manage organisational priorities and clients' expectations, rationing services and 'conserving scarce organisational and personal resources' (Lipsky, 2010: 190). The ways in which I\&SM are woven into these complex and continuously renegotiated spaces is the empirical subject of the article.

\section{Research setting and methods}

The research was undertaken in three contiguous local authority wards in a northern city of England ranked in the 10 per cent most deprived by the UK government's Indices of Multiple Deprivation ${ }^{1}$. Formerly populated by mainly white working class residents, these wards now host diverse ethnic and national minorities. The area has experienced several regeneration initiatives but deep social and economic problems remain. Youth unemployment is high and educational achievement is low by national standards. Most fieldwork was undertaken in the final quarter of 2012 with follow-up interviews in 2013. Fieldwork consisted of three elements. First, overt observation was undertaken of three workshops set up by a youth organisation. These workshops aimed to encourage practitioners to think about how they could use social media and involved twenty-nine practitioners and eight 14-18 year olds. Second, semistructured interviews were conducted with fifteen workers in thirteen youth sector organisations 
(see, Table 1). Snowball sampling was used for recruitment following workshop participation. Third, four public sector IT professionals were interviewed.

The research organisations varied from local authority units and social enterprises to charitable and community groups. Interviewees had a range of roles and job titles. For analytical purposes_the article refers to 'managers' and 'frontline practitioners', though there is overlap between the categories as, for example,, some managers remain involved in casework. There was an even gender balance and the age distribution ranged from early 20 s-50s. Interview schedules were designed to probe the degree to which practitioners are utilising I\&SM in and out of the workplace. Lines of inquiry included levels of understanding in regards to popular social media among young people, what practice opportunities they foresaw with these tools and perceived barriers in their use. Interviews were transcribed, coded and then categorised into several themes descriptively. The precise locations are witheld for reasons of confidentiality and to preserve anonymity 
Table 1: Profile of Interviewees

\begin{tabular}{|c|c|c|c|c|}
\hline Occupation & Employer & Gender & Age & Interview date \\
\hline Senior Manager & Local authority & Male & Mid 50s & 8 October 2012 \\
\hline Community Worker & As above & Female & Late 30s & 8 October 2012 \\
\hline Manager & $\begin{array}{l}\text { Social enterprise catering for } 8-25 \text { year olds through a suite of } \\
\text { different programmes and activities. }\end{array}$ & Male & $\begin{array}{l}\text { Early } \\
30 \mathrm{~s}\end{array}$ & 9 October 2012 \\
\hline Acting Director & Local community centre. Greatest provision is youth-focused. & Female & Mid 40s & 11 October 2012 \\
\hline Junior Youth Worker & As above & Female & $\begin{array}{l}\text { Early } \\
20 \text { s }\end{array}$ & 11 October 2012 \\
\hline Senior Manager and Youth Worker & $\begin{array}{l}\text { Social enterprise with emphasis on employability among young } \\
\text { people. }\end{array}$ & Male & Mid 40s & 12 October 2012 \\
\hline Chief Executive & A youth worker advisory service which operates regionally. & Male & Mid 40s & 17 October 2012 \\
\hline Senior Youth Worker & $\begin{array}{l}\text { Freelance practitioner who engages young people in a range of } \\
\text { creative/curative activities across the region. }\end{array}$ & Male & Mid 30s & 17 October 2012 \\
\hline Director - Charity & $\begin{array}{l}\text { Charity specialising in community engagement with women } \\
\text { only, including young women and girls. }\end{array}$ & Female & $\begin{array}{l}\text { Early } \\
40 \text { s }\end{array}$ & 19 October 2012 \\
\hline Founding Director & $\begin{array}{l}\text { Social enterprise specialising in out-of-school tuition and peer } \\
\text { mentoring among young people and with university students. }\end{array}$ & Female & Mid 40s & 21 November 2012 \\
\hline Youth Worker - SME & As above & Female & Mid 20s & 21 November 2012 \\
\hline Community Worker & $\begin{array}{l}\text { Registered charity providing a range of gendered support } \\
\text { services. }\end{array}$ & Female & Late 40 s & 24 November 2012 \\
\hline Youth Worker - BME Specialist & $\begin{array}{l}\text { Charity specialising in engagement activities with young people } \\
\text { from black and ethnic minority (BME) communities. }\end{array}$ & Female & $\begin{array}{l}\text { Early } \\
30 \text { s }\end{array}$ & 27 November 2012 \\
\hline Youth Worker - National Charity & $\begin{array}{l}\text { National charity with a regional branch in the focus city. } \\
\text { Specialist in developing skills for work. }\end{array}$ & Male & Mid 20s & 22 November 2012 \\
\hline Founding Director & $\begin{array}{l}\text { SME which develops the web presence of clients. Experience } \\
\text { with the region's youth sector and potential employer. }\end{array}$ & Male & Mid 20s & 12 December 2012 \\
\hline
\end{tabular}




\section{Enacting I\&SM on the Frontline: the case of Youth Work}

\section{Enacting I\&SM within youth work organisations}

As with other UK public services, the youth sector has been criticised for the slow adoption of social media and in adapting its practices to the digital age (Gibson, et al., 2010; HM Government, 2012). A Local Government Innovation Unit survey found that just 25 per cent of local authority organisations were using social media in youth and/or social work. It has been suggested that youth workers lack skills and knowledge of the new technologies (Ali and Davies, 2009; Davies and Cranston, 2008; HM Government, 2011). Evidence from this study broadly confirms the limited utilisation of social media but reveals a far more complex pattern.

Most interviewees did use social media in their personal lives although, as would be expected, to different degrees. In the workplace, social media were being adopted for both intraand inter-organisational purposes. Facebook, Twitter and YouTube were embedded into administrative, communications and evaluative processes. In addition, youth workers were using social media to manage professional, peer-to-peer relationships at local and national levels. Facebook pages connected past and present youth sector volunteers, while other platforms promoted work with young people to funders. Efforts were being made to communicate with and engage young people by electronic means. All contributing organisations had websites accessible to clients but a review of these sites indicates limited content and basic interactivity. Social media were also used to disseminate information to clients. For example, Facebook 'walls' were replacing printed flyers as the key means of drawing attention to events. Some organisations were taking further tentative steps, integrating I\&SM in developmental work. One organisation was getting young people to work with social media as part of a youth 
unemployment campaign. Another had woven YouTube into 'Friday night chill sessions'. A third was working with artists who routinely involved social media interactively in their sessions by, for example, co-creating short film clips. Attempts had also been made to facilitate online interaction between groups of young people though this had proved problematic.

One organisation was considering how online social networking might be used to overcome young people's 'desire not to go beyond their own postcodes' and to encourage interaction across geographical wards. Another was looking to support organic, communitygenerated activities. The latter included a scheme seeking to link young people from black and minority ethnic (BME) groups with cohorts in the United States and South Africa via Facebook and Instagram. However, initiatives tend to be tentative, piecemeal and suggest that social media has only a limited impact on routines and practices. The remainder of this section considers the challenges identified by interviewees in further pursuing I\&SM.

The first challenge was resource constraint, long identified as a factor impeding ICT innovation in the public and third sectors. Austerity has exacerbated this situation. Most interviewees reported that their organisations had experienced job cuts and reduced working hours. A senior manager noted that his team had been cut from four people to 'one and a bit' in two years while the founding director of another organisation pointed to a fall in contracted hours which constrained service delivery. One youth worker explained:

Without saying that everything was rosy before...it's worse now. My colleague's hours are reduced to eighteen from thirty and there is no[one] to work with other than for seven hours a week. That's one session together which is a forty-five minute schools session (Interview, BME Specialist).

Interviewees also reported the added pressure arising from the reliance on short-term funding 
via competitive tendering for 'small pots' of project-based funds with tight deadlines.. A community worker reported:

We haven't received any grant aid from [the] Council. That used to fund the Tuesday club and a little left over. But the rest is private trusts and charities and I mean, how much money can you make selling jam and cupcakes? [Our Director] never started this in order to sit and fill in funding applications all the time and that's the way it's turned out.

Schumpeterian theory might suggest that these pressures would lead to 'creative destruction' but in reality, they have created unpropitious conditions for experimentation. Already overstretched workers are struggling to adopt, manage and monitor new technologies, let alone undertake radical innovation. A key part of the 'digital by default' narrative is that innovative adaptation to I\&SM will result in savings and allow local organisations to 'do more for less'. This outcome was not the perception of respondents. Additional costs resulted from having to integrate new channels into work processes and having to update legacy systems, a problem worsened by the tendencies of young people to use mobile technologies (which some websites do not support) and high social media platform 'churn'. All interviewees stressed the continued importance of face-to-face working and of drawing diverse client groups together in collective settings. I\&SM was seen as complementary to current activities rather than a substitute and so managers did not foresee cost savings in the medium term. Efficiency savings were identified at the margins, through easier communication with clients and I\&SM's abilities to capture, edit and upload evidence of community activities in situ, so avoiding a return to the office.

A second challenge relates to skills and levels of awareness. Nearly all interviewees expressed concern about their own level of knowledge of I\&SM. These anxieties were mainly articulated in terms of their position relative to other groups. Managers saw themselves as not 
being as up-to-speed with I\&SM as frontline staff. Both groups perceived themselves to be less aware than clients, attributing this difference mainly to age. A flavour of attitudinal differences can be gained from the following extracts from a joint interview with a manager and a youth worker in her twenties:

I just don't understand them... young people seem to spend all their time on Facebook and spending a lot of time growing virtual crops and it's just like "what?", "what are you doing?" (Interview, Acting Director).

I mean, if someone doesn't have Facebook it's weird...it's just like the norm now and if you don't have Facebook you're strange, you know? Perhaps if you don't have Facebook you just don't like social media, but it's just that the majority of [younger volunteers] have it (Interview, Junior Youth Worker).

Generally, managers claimed to be too busy with operational matters to acquire additional ICT skills. The integration of I\&SM was delegated to junior staff:

We have a YouTube and we have a Facebook but I don't really do it. I have people go on and do it, even my page. I have people going on and posting stuff because I just don't have time to do it (Interview, Manager).

The capabilities of younger staff were appreciated by managers as a valuable, innovative resource. However, there was a perception that younger workers had to be protected lest they import practices from their personal world into the workplace without being aware of the dangers to themselves or their organisation. Managers spoke of a need to avoid making 
inappropriate postings or broadcasting to people for whom the information is not intended. Some younger staff felt frustrated at these extra responsibilities for I\&SM while being constrained in how they could utilise them.

A third challenge pertains to the need to balance practice-based innovations with organisational safeguards. A key theme in the workshops was uncertainty in regards to utilising I\&SM and the lack of guidance from central government, regulatory standards, bodies and professional associations. A senior youth worker suggested that organisations were 'fumbling through'. During fieldwork, the relevant local authority had produced only a general statement about the use of I\&SM. Interviewees complained that this statement did not take into account the differing roles of individual council departments or units, nor agencies to whom it contracted work. A four-page 'safeguarding' checklist for vulnerable groups was available but was not tailored to the meet the needs of different client groups. For example, the Council's YouTube policy was to simply 'block access'. However, for one youth organisation, access to the platform was crucial to 'Friday night chill' sessions with older teens. This combination of vagueness and prescriptiveness left local public and third sector managers and practitioners making decisions on issues with which they had little experience. All the managers interviewed had developed some form of internal protocol in lieu of external advice. However, it was not clear how systematic the design of these protocols was. One manager drew on guidance from the National Society for the Prevention of Cruelty to Children (NSPCC) and the work of other local authorities that had developed policies in this area. Yet, this was time-consuming and much effort was expended on protective tactics rather than the experimentation imagined by policymakers.

The following examples illustrate the difficulties organisations were facing. Practitioners had to determine what they should and should not be uploading and downloading, when and 
how to gain informed consent and how to ensure the security of photographs, text or video which often included details of the young people with whom they had contact. They had to assess how to use I\&SM in transparent and client friendly ways without 'oversharing' or creating the potential for transgressions of existing relationship boundaries. Similarly, individual workers had to protect themselves on personal sites to develop barriers between their personal and work lives, particularly measures to avoid being 'friended' in a personal capacity rather than as a youth worker. Several practitioners said that they had developed 'multiple online faces' that were personal, organisational and professional, requiring the management of several social media accounts. The level of resources needed to ensure the safety and security of stakeholders - organisation, workers and clients - leaves little time for radical innovation. A national charity youth worker described the experience of adapting to the new technology landscape, suggesting that 'there isn't anything that tells you how to use it the right way. I mean, it's just there isn't it?'

Enacting technologies at the practitioner-client interface

The perceived digital divide between practitioner and client is more pronounced than within the workplace. All interviewees expressed the perception that young people have the latest technologies and are adept at using them. For example, one youth worker who provides learning support said:

I know the majority of young teens we have coming here these days are all on their BBM-ing [Blackberry Instant Messenger] and texting each other and emailing and Facebook. They all have them, trust me (Interview, Youth Worker - SME). 
Other practitioners in their twenties and early thirties believed themselves to be far less techsavvy than clients:

...they'll be like "oh but she's so skinny!", "did you go there?”, "did you do this?”, "did you do that?" It's all looking at BBM or Facebook and it goes like a 1,000 miles per minute you know? It is quite you know? I get quite concerned for them you know? Because I mean when I was their age you know, we had books (Interview, Junior Youth Worker).

..that's how the young people now communicate with each other. So you know, social media is happening [in the study area] and I'm not up on all this stuff. I am from a different generation. So to be honest with you, it's all new to me. Erm, but I think young people are using it all the time. They just pick it up! They know what they're doing and you know, straight away they know what they're doing as well. It's just amazing (Interview, Youth Worker - National Charity).

The sense of wonder among younger workers with regard to their clients' technical facility was balanced with concern for what they saw as naivety. In the workshops, participants worried about the immediate risks posed by young people's uses of tools like Facebook. Drawing on recent media reports and anecdotes from fellow professionals, online bullying and concerns over the effects of 'digital footprints' on future life chances were particular concerns. The founding director of an SME that has worked with a range of youth organisations to develop their social media presence added that 'young people are not treating the internet with respect', meaning that they did not recognise the dangers of communicating in public spaces often assumed to be private. Another manager reflected on young people's 'cavalier' attitude: 
It's really personal stuff from what I see on our projects. Young people are always [mimics holding a smartphone] you know, “look what that person's put up on here!". And sometimes I'm like, I can't believe they've done that or gone there. It's really personal stuff (Interview, Senior Manager and Youth Worker).

Young people's lack of awareness about the potential consequences of online activity was also clear in the workshops. Young participants were surprised or outraged when presented with examples of people being imprisoned for social media activity during the UK riots of 2011.

The concerns of practitioners which emanate from direct experiences with young people are underscored by the nature and volume of media coverage. Although concerned with the possible effects of young people's online behaviours on short and long-term wellbeing, practitioners did not have a clear view as to how to address the issue. Overall, interviewees felt hesitant about expressing views because, as adults, they would be regarded as technological dinosaurs. Consequently, it was difficult to bring (non-technological) life experience to bear in extending their duty of care into these new areas of social activity. One organisation did attempt to provide advice as part of a course designed to help unemployed young people to sell their skills to employers. Youth workers undertook a basic Google search and presented their students with publicly available facts about themselves, an exercise that was intended to show the ease with which employers might access personal personal information that might influence their hiring decisions. This was designed as a 'fun activity' but nonetheless proved a delicate process requiring careful thought about the types of material taken from I\&SM so as to not undermine trust.

Interviewees described the dilemma of balancing experimentation while retaining a degree of control. Failed attempts at opening up online spaces of communication were reported by several youth workers. Such failings were usually due to what was regarded by interviewees 
as 'poor behaviour' by clients. For example, one interviewee described how she had set up a Facebook page only to find that the young people with whom she worked set up another with the specific purpose of undermining the original. Another was less concerned with purposeful disruption and instead stressed the difficulties in innovating in online spaces whilst retaining authority. The chief executive of one organisation explained how he and his team had created social media spaces to encourage interaction between young people. A Facebook page was set up to support youth-led 'specialist groups' to explore social issues affecting young peoples' lives. It was hoped that Facebook would help foster collective identity, exchange and promote skills independence and initiative. The specialist group consisted of core members who met face-to-face and another group who only engaged online. However, there was a falling out in one of the face-to-face meetings when one member insulted another. This was followed by aggressive posts on Facebook and the argument escalated as others joined in. This conflict played out over a weekend so was not monitored by the organisation.

A further example of young people using Facebook to 'vent anger about situations in inappropriate ways' involved a heated discussion over the suitability of an apprentice youth worker for a new role. When the organisation intervened to moderate the online discussion, some participants, in the words of the interviewee, argued that the Facebook page 'is our space and we can say what we want'. While in this case the organisation had administrative rights and was able to suspend the page, in another case, a young person had set up his own Facebook page and linked it to the organisation. The organisation then became wrongly associated with content it had not approved, causing potential reputational damage. In each case, youth workers had to intervene through formal, face-to-face meetings in order to try and resolve conflict and regain control. Such cases illustrate the tensions that can come to the fore in efforts to innovate with I\&SM. While the chief executive remains committed to social media, he 
questioned whether smaller organisations and funders would have the capacity or appetite to take similar risks.

Beyond experimental spaces, interviewees expressed no desire to view what young people were up to via I\&SM though they were well aware of the potential to observe clients through Facebook and other platforms. A national charity youth worker explained how it would be possible to access personal profiles and see what clients are doing at any given time on a Saturday night. However, interviewees were conscious that young people would not want them entering these spaces and transgressing could undermine trust.

Practitioners were aware from personal experience of the ways in which social media can draw people into viewing what their friends do and did not want this to extend into work. However, youth workers cannot wholly avoid clients' online activity and there are occasions when posts come to the attention of workers:

There have been situations where somebody has said to me "have you seen so and so's Facebook page?" And I think "no! I really would rather not know". But obviously when things get brought to my attention I have to deal with it. [In some cases] your job would be to immediately take action under the safeguard procedure. That might seem extreme, but it's not because those issues are so common in terms of sexual violence, domestic violence and all those kinds of things (Interview, Acting Director).

Several interviewees reflected on the complexity of interpreting online messages compared to face-to-face communication, identifying two issues in particular. The first was the reduced richness of cues and the second, the different ways individuals present themselves online: 
I think social media can blur [understanding] in a way that face-to-face contact also still does but it's easier to sit there and think, "wait a minute, are they telling me something I need to report?" in a face-to-face setting (Interview, Junior Youth Worker).

Another potential barrier to experimentation and innovation with I\&SM is the way in which 'digital footprints' can be reviewed later by managers, regulators or even the media. Interviewees reported that safeguarding procedures are already so strong that most err on the side of caution with their duty of care. The additional transparency of I\&SM reinforces risk aversion and may reduce the potential for youth workers to have 'a quiet word' or to make an advisory intervention where the situation is less serious.

A final aspect of boundary blurring and oversharing is temporal in the sense of clients' increasing expectation of around-the-clock availability which impinges heavily on work-life balance. Older workers had already experienced greater demands following the growth of mobile telephony. In the context of I\&SM, these demands apply to both attempts by clients to contact workers, and to 'passive sharing' where a communication is picked up by a practitioner. One interviewee provided a detailed account of how such a scenario can unfold:

I had this awful experience where this young person had made suicidal comments on Facebook. [...] I was due to finish work and so I didn't even get the chance to look at where this teenager was from. But this young person was actually from the US [United States] which I didn't know at the time! I sent a message pointing her to Childline [a national support charity/helpline]. They then put me on some kind of internet abuse line who said it wasn't their concern. And then they wanted me to call the police. The police were actually very good in locating this person in the US but they couldn't actually do anything about it. Luckily, the next day, she posted up on her [Facebook] wall that someone had come to her house to 
stop her. I mean, I don't usually react as people are always posting up their emotional state on Facebook and stuff you know? But I looked at this young person's history and she hadn't made these statements before (Interview, Youth Worker - BME Specialist).

This final quote illustrates how I\&SM can bring additional pressures to frontline workers. Taking a safety first approach, consistent with professional codes and personal ethics, means an increased workload in respect of expanded duty of care beyond office hours. It also raises the question of where geographical bounds lie in the duty of care. In this extreme case it becomes global.

\section{Discussion and conclusions}

As e-government expands, more public service workers are utilising_digital technologies in everyday work. This article has focused on how one configuration of new, new technologies (Howcroft and Taylor, 2014) (I\&SM) is being enacted in the context of frontline public service activities.

The evidence presented suggests that youth work organisations are tentatively engaging with I\&SM but that innovation is limited. A number of challenges have been identified which impede further adoption. Some challenges mirror those associated with the introduction of earlier waves of ICTs, notably resource constraints, problems of leadership, skills deficits, safety and security and generalised risk aversion. Additionally, there is limited awareness of the potential of the new technologies. These findings are supported by recent studies that examine the adoption of social media in public services explicitly (Slee and Caveney, 2013). These 
factors taken together, and as suggested by Fountain in respect of earlier rounds of technology, constrain the ways in which technology is enacted within organisations.

A significant literature on I\&SM in the social sphere suggest new communication practices are emerging. Tendencies include the creation of 'multiple selves' (particularly amongst young people), 'hyperconnectivity', 'over-sharing' and the breaking down or blurring of social and institutional boundaries (Agger, 2012; Baym, 2010; Lovink, 2011; Rainie and Wellman, 2012). This article suggests that the practices are now seeping over into the sphere of work and that the intersection of practices between social and work lives may be a fruitful research area in relation to 'new new technologies'.

In terms of intra-organisational relationships, the study has made clear that individual workers exhibit different attitudes and expectations in regard to I\&SM as it penetrates work routines. Consistent with the findings of Brooke and Taylor (2005), the main variable appears to be age, with older workers being more conservative. However, age is often associated with seniority which, in turn, brings responsibility for managing risk and protecting the organisation, staff and clients. Thus, care should be exercised in attributing risk aversion solely to age. Risk aversion may of course be the rational option when, for instance, attempting to balance the connective properties designed into platforms like Facebook and Twitter with the need to maintain professional distance from clients. Nevertheless, age-seniority related knowledge asymmetries can cause tension. Accordingly, some younger interviewees were resentful that while they tended to have responsibility for mplementing I\&SM, less technologically adept managers controlled strategy and the pace of innovation.

There is a wider point to be made here regarding frontime social services and how the differentiated experiences of I\&SM in the social sphere translates into the workplace. In contrast to previous waves of ICTs which have involved individuals coming to new technologies via the 
workplace, many people now come to I\&SM in their social life first. Sociomaterial practices are frequently formed outside the workplace and then imported into work settings. This trend is underpinned by workers using their own devices (BYOD) either at the behest of the employer or by their own choice (Galloway et al., 2014). This development presents challenges for the worker and for their organisation. From an organisational perspective, there is a need for innovation to maximise the benefits of ICT (Brynjolfsson and Saunders, 2010). However, this objective could compromise network security and reputational integrity (Morrow, 2012; Silverman, et al., 2013; Thomson, 2012). The variety of external experiences could also be interpreted as an opportunity for public service organisations. For example, creating conditions within which multiple viewpoints of workers can be expressed and allowing 'employee voice' to travel up the hierarchy for more informed digital strategies (Silveman, et al., 2013).

In respect of practitioner-client interfacing, a key challenge for youth organisations is how to integrate I\&SM effectively without upsetting delicate, trust-based relationships which are under constant negotiation and central to remaining 'friends with authority'. There are several issues here. First, a perceived knowledge asymmetry between practitioners and clients with respects to younger people being more technically proficient than themselves but also socially naïve in their online practices. Second, uncertainty over which online spaces could be shared and under what circumstances. Third, the open nature of social media traffic means that youth organisations are sometimes privy to communications not directed to them. The latter often require an intervention which is not always easy to judge, particularly when interpreting online cues is more difficult than face-to-face ones. Even where online shared spaces were purposefully created through negotiation with clients, difficulties had emerged as a result of client behavior. The overall impression is of additional activities and responsibilities forcing practitioners to negotiate multiple online and offline spaces. 
Distinct processes of deboundarying appear to be in play in our research organisations as practices emerge around I\&SM. These require further theorisation individually and as a set of collective sociomaterial practices. The first is the deboundarying of professionals' work-life. The second is deboundarying of relationships between organisation-professional and client. These developments have implications for organisational theories relating to digital technologies. Tentatively we suggest that three interrelated processes are occurring. The first is the differentiated enactment of the 'intrinsic' properties of technologies by different actors, dependent not just on broad categories such as age but also personal characteristics such as attitudes to openness, privacy, exhibitionism, and so on which in turn may be based on life experiences. The second is different and variable approaches by the same individuals as they enact technologies in different spheres of their lives. Here there are potential tensions as individuals import skills, attitudes and habits developed in the social sphere into the workplace. This observation contrasts with, or at least adds an additional layer to, Orlikowski's (2007) analysis of Blackberry use amongst professionals where she accounts for practice through a combination of the sociomaterial configuration to 'push mail' with professionals' scanning of mail as part of the culture of the organisation and or the profession. However, it is being suggested here that habit formation in the non-work sphere may be as important and that importing these practices into a (vulnerable) client facing setting may carry additional dangers beyond those associated with being 'always on' for work colleagues. The third process is the way that actors and the 'materiality' of I\&SM are converging in ways not intended by their designers. That is to say technology applications such as Facebook which were primarily (initially at least) designed for peer groups are encroaching on spaces where interaction is between those assigned specific and distinct roles by society, and where 'institutional norms' require or demand separation. 
The practitioner-client relationship is then a key contextual element in which new technologies will be enacted in SLB settings. The neo-taylorist standardisation approaches applied across 'customer services' (Bain and Taylor, 2000) are not appropriate and 'smiling down the phone' (Belt et al., 2002) will not easily substitute for the intricate, trust-based relations of SLB work. Clients not only form an important part of the context within which I\&SM are enacted but they are also active agents in the enactment of these tools. New technologically mediated relations need to be co-created. This study has made clear that this is not an easy task. Limited evidence suggests that other professions may face similar challenges (Reamer, 2013). There will also be challenges specific to their particular client base. So, for example, health or care practitioners dealing with older clients may need to manage a fear of technology and to raise clients' digital awareness (Abbott and Richardson, 2013). Social work professionals, psychologists and psychotherapists may focus more on individuals or families rather than on the group work which characterises the youth sector. These individual relations may be deeper and practitioners will need to negotiate the spaces constructed via I\&SM interactions accordingly as, for instance, in managing 'attachment'. Further research is required to understand the commonalities and differences across and between different practitionerclient settings. Similarly, another area of potential research is variation in geographical settings. This article has concentrated exclusively on England but e-government is now a global development. Comparative research on I\&SM in youth work and other SLB contexts may indicate how professional norms play out in different national welfare systems.

Finally, in terms of policy and practice more work is required to inform and develop guidance and protocols for public service practitioners. One key theme to emerge from this study of youth work was the lack of advice and guidance. This absence was felt by both managers and workers and was described as a major barrier to innovation, meaning that more 
focus was given to protective measures. These issues are not unique to frontline public services (Institute of Business Ethics, 2011; Silverman, et al., 2013). However, it can be argued that they have added significance in public services for a number of reasons. Clients are often extremely vulnerable and information can be peculiarly sensitive. The establishment of protocols is also important to protect SLB organisations and workers in the search for new ways of working. Advice is beginning to emerge from trade unions and professional associations (Garner, 2014) but more needs to be done at a governmental level in formulating general rules and guidance and more directive sector specific advice. It is not, of course, a straightforward matter to lay down such rules when, to quote Raine and Wellman (2012: 105), 'norms of networked individualism have not caught up with the practices of networked individualism'. That is to say that I\&SM practices are emergent and acceptable behaviours, forms of validation and trust mechanisms are still being negotiated. There is, as yet, no agreed 'netiquette'.

\section{References}

Agger, B. (2012), Oversharing: Presentations of Self in the Internet Age (New York: Routledge). Ali, J. and T. Davies (2009), Social Media: Youth Participation in Local Democracy (London: Local Government Information Unit). Available: http://www.local.gov.uk/localism-act//journal_content/56/10180/3511562/ARTICLE (accessed 20 February 2014).

Aydin, S. (2012), 'A Review of Research on Facebook as an Educational Environment', Educational Technology Research and Development 60, 6, 1093-1106.

Ayres, S. (2013), 'Social Media for Social Care: A Guide to Online Tools', Guardian Professional, 03/06/13. Available: http://www.theguardian.com/local-governmentnetwork/2013/jun/03/social-media-social-care-councils (accessed 04 February 2014).

Bain, P. and P. Taylor (2000), 'Entrapped by the "Electronic Panoptican"? Worker Resistance in the Call Centre', New Technology, Work and Employment 15, 1, 2-18.

Baines, S., R. Wilson and S. Walsh (2010), 'Seeing the Full Picture? Technologically Enabled Multi-Agency Working in Health and Social Care', New Technology, Work and Employment 25, 1, 19-33.

Batlajery, B. V., R. Khadka, A. M. Saeidi, S. Jansen and J. Hage (2014), Industrial Perception of Legacy Software Systems and their Modernization, Technical Report UU-CS-2014-004 (Utrecht, The Netherlands: Utrecht University Technical Reports). Available at http://www.cs.uu.nl (accessed 18 February 2014).

Barnes, S. (2006), 'A Privacy Paradox: Social Networking in the United States', First Monday 11, 9, Online Journal, http://firstmonday.org/article/view/1394/1312. 
Baumer, S. (2013), 'Social Media, Human Connectivity and Psychological Well-being', in S. Price, C. Jewitt and B. Brown (eds), The Sage Handbook of Digital Technology Research (London: Sage), pp. 71-87.

Baym, N. K. (2010), Personal Connections in the Digital Age (Cambridge, UK: Polity).

Belt, V., R. Richardson and R. Webster (2002), 'Saved by the Bell: Women, Skills and Interactive Telephone Work in Call Centres', New Technology, Work and Employment 17, 1, 20-34.

Beresford, M. (2014), Smart People Smart Places: Realising Digital Local Government. Report to New Local Government Network. Available at http://www.nlgn.org.uk/public/2014/smartpeople-smart-places-realising-digital-local-government/ (accessed 14 February 2015).

Brooke, L. and P. Taylor (2005), 'Older Workers and Employment: Managing Age Relations', Ageing and Society 25 3, 415-429.

Broughton, A., T. Higgins, B. Hicks and A. Cox (2010), Workplaces and Social Networking: The Implications for Employment Studies (Brighton: ACAS). Available: Available: http://www.acas.org.uk/media/pdf/f/q/1111_Workplaces_and_Social_Networking-accessibleversion-Apr-2012.pdf (accessed 11 February 2015).

Brown, A. D., S. Ainsworth and D. Grant (2012), 'The Rhetoric of Institutional Change', Organization Studies 33, 3, 297-321.

Brynjolfsson, E. and A. Saunders (2010), Wired for Innovation - How Information Technology is Reshaping the Economy (Cambridge, MA: MIT Press).

Buckland, L. (2013), 'Positive for Youth. A Critique', The Encyclopedia of Informal Education, http://infed.org/mobi/positive-for-youth-a-critique/ (accessed 17 February 2014).

Burton, J. and D. van den Broek (2009), 'Accountable and Countable: Information Management Systems and the Bureaucratization of Social Work', British Journal of Social Work 39, 13261342.

Byron, T. (2010), Do we have Safer Children in a Digital World? A Review of Progress Since the 2008 Byron Review (London: DfE, DCSF-00290).

Cabinet Office. (2005), Transformational Government: Enabled by Technology (London: HMSO, Cm 6970).

Cabinet Office. (2012), Government Digital Strategy (London: HMSO).

Cabinet Office. (2014), Government Digital Inclusion Strategy (London: HMSO).

Cabinet Office. (2014), Social Media Guidance for Civil Servants (London: HMSO).

Carr-West, J., A. Johnston, J. Sillett, J. Ali and A. Walker (2009), Local Government 3.0: How Councils Can Respond to the New Web Agenda (London: Local Government Information Unit). Available:

http://www.local.gov.uk/localismact/journal_content/56/10180/3511562/ARTICLE (accessed 04 March 2014).

Carter, R., Danford, A., Howcroft, D., Richardson, H., Smith, A. and Taylor, P. (2011), "'All they lack is a chain": Lean and the New Performance Management in the British Civil Service', New Technology, Work and Employment 26, 2, 83-97.

Chadwick, A. (2009), 'Web 2.0: New Challenges for the Study of E-Democracy in an era of Informational Exuberance', Journal of Law and Policy for the Information Society 5, 1, 9-42.

Cornford, J., B. Wessels, R. Richardson, A. Gillespie, I. McLoughlin, J. Kohannejad, V. Belt and M. Martin (2003), Local Egovernment: Process Evaluation of the Implementation of Electronic Local Government in England (London: ODPM).

Coyle, D. (2009), Reboot Britain: How the Promise of a New Digital Age Can Tackle the Challenges we Face as a Country (London: NESTA). Available:

http://www.nesta.org.uk/publications/reboot-britain-essays (accessed 13 October 2013). 
Dale, R. (2012), Local 2.0: How Digital Technologies Empower Local Communities (London: Local Government Information Unit). Available: http://www.lgiu.org.uk/2012/06/12/local-2-0how-digital-technology-empowers-local-communities/ (accessed 2 February 2015).

Davies, B. (2010), 'What do we mean by Youth Work?', in J. Batsleer and B. Davies (eds), Learning Matters: What is Youth Work? (Exeter: Learning Matters), pp. 1-7.

Davies, T. and P. Cranston (2008), Youth Work and Social Networking (Leicester: National Youth Agency). Available: http://www.practicalparticipation.co.uk/publications/ (accessed 11 October 2013).

Davies, B. and E. Wood (2010), 'Youth work practice within integrated youth support services', in J. Batsleer and B. Davies (eds), Learning Matters: What is Youth Work? (Exeter: Learning Matters), pp. 73-90.

Denham, K. (2013), 'Councils Embrace Social Media', The Guardian, 23.05.13. Available: http://www.theguardian.com/local-government-network/2013/may/23/local-authoritiesembrace-social-media (accessed 08 August 2014).

Department for Communities and Local Government. (2010), The English Indices of Deprivation (London: HMSO).

Department for Communities and Local Government. (2013), 'Local Digital Today', [Online]. http://www.gov.uk/government/publications/local-digital-today (accessed 26 February 2014).

Department for Education. (2013), 'Increasing Options and Improving Provision for Children with Special Educational Needs', [Online]. https://www.gov.uk/government/policies/increasingoptions-and-improving-provision-for-children-with-special-educational-needs-sen (accessed 07 February 2014).

Dunleavy, P., H. Margetts, S. Bastow, J. Tinkle (2006), Digital Era Governance: IT Corporations, the State and E-Government (Oxford, UK: Oxford University Press).

Education and Inspections Act 2006. (c.40). London: HMSO.

Ellison, N. and M. Hardey (2013), Developing Political Conversations: Social Media and English Local Authorities. Information, Communication and Society 16 6, 878-898.

Ellison, N. B., Steinfield, C. and Lampe, C. (2011), 'Connection Strategies: Social Capital Implications of Facebook-enabled Communication Practices', New Media and Society 158 , 873-892.

ENISA. (2011), 'Cyber-bullying and Online Grooming: Helping to Protect against the Risks', [Online]. http://www.enisa.europa.eu (accessed 17 March 2014).

Farvaque, N. and J-P. Yonnet (2007). Job creation in innovative relational services: the case of services to private individuals in Europe. Brussels: European Commission, http://orseu.com (accessed February 2014).

Fountain, J. E. (2001), Building the Virtual State; Information Technology and Institutional Change (Washington, D.C: Brookings Institution Press).

Galloway, J., M. John, and M. McTaggart (eds) (2014), Learning with Mobile and Handheld Technologies (London: Routledge).

Garner, R. (2014), 'Anti-Bullying Week: Teachers Warned not to Befriend Pupils on Facebook as they Risk Being Victims of Cyber-bullying too', The Independent, 16.11.14. Available: http://www.independent.co.uk/news/education/education-news/antibullying-week-teacherswarned-not-to-befriend-pupils-on-facebook--as-they-risk-being-victims-of-cyberbullying-too9864008.html (accessed 16 November 2014).

Gibson, A. (2010), Local by Social: How Local Authorities can use Social Media to Achieve More for Less (London: NESTA). Available: http://www.nesta.org.uk/publications/local-social (accessed 2 March 2014).

Gibson, G., McCusker, P. and Taylor-Smith, E. (2010), 'Online Tools and their Impacts on 
Young People', $10^{\text {th }}$ European Conference on eGovernment, University of Limerick, Ireland, [Online]. http://www.iidi.napier.ac.uk/c/publications/publicationid/13361641 (accessed 2 March 2014).

HM Government. (2011), An Agenda for Youth Engagement: Government Response to the Recommendations of the Youth Citizenship Commission (London: HMSO). HM Government. (2012), Positive for Youth (London: HMSO).

Harrison, A. (2013), 'Cyber-bullying: Horror in the Home', BBC News, 10.10.13. Available: http://www.bbc.co.uk/news/education-23727673 (accessed 11 February 2014).

Hawn, C. (2009), 'Take Two Aspirin and Tweet Me in the Morning: How Twitter, Facebook and other Social Media are Reshaping Health Care', Health Affairs 28 2, pp 361-368.

Heeks, R. and S. Bailur (2006), 'Analyzing E-government Research: Perspectives, Philosophies, Theories, Methods and Practice', Government Information Quarterly 24, 243265.

Hope, C. (2013), 'Facebook is a "Major Location for Online Child Sexual Grooming" Head of Child Protection Agency says', Daily Telegraph, 15.10.13. Available:

http://www.telegraph.co.uk/technology/facebook/10380631/Facebook-is-a-major-location-foronline-child-sexual-grooming-head-of-child-protection-agency-says.html (accessed 15 February 2014).

Howcroft, D. and Taylor, P. (2014), "Plus ca change, plus la meme chose": Researching and Theorising the 'New New Technologies', New Technology, Work and Employment, 29, 1, 1-9. Institute of Business Ethics. (2011), The Ethical Challenges of Social Media (London: IBE). Available: http://www.ibe.org.uk/ (accessed 14 February 2015).

Jeffs, T. and M. K. Smith (1999), 'The Problem of "Youth" for Youth Work', Youth Policy 64, 4566.

Kaifeng, Y. (2003), 'Neoinstitutionalism and e-Government: Beyond Jane Fountain', Social Science Computer Review 21, 4, 432-442.

Kelion, L. (2013), 'Facebook lets Beheading Clips Return to Social Network', BBC News, 13.10.13. Available: http://www.bbc.co.uk/news/technology-24608499 (accessed 10 March 2014).

Kingsbury, J. (2010), Towards Public Service 3.0 (London: NESTA). Available:

http://www.nesta.org/blog/towards-public-services-3.0 (accessed 14 February 2014).

Kimball, E. and J. R. Kim (2013), 'Virtual Boundaries: Ethical Considerations for Use of Social Media in Social Work', Social Work 58 2, 185-188.

Kuchler, H. (2013), 'Facebook Admits to Losing Young Teen Users', Financial Times, 30.10.13. Available: http://www.ft.com/cms/s/0/02ec9e24-41a0-11e3-907300144feabdc0.html\#axzz3MFyN0lu9 (accessed 10 November 2013).

Laffin, M. and C. Ormston (2013), 'Disconnected Communities? ICT, Policy Learning and the Lessons for Central-local Relations', Public Money and Management 33 3, 185-191.

Leadbeater, C. (2009), We-Think: Mass Innovation and not Mass Production (London: Profile).

Lenhart, A., K. Purcell, A. Smith and K. Zickuhr (2010), 'Social Media and Mobile Internet use among Teens and Young Adults', Pew Internet and American Life Project, 1-37.

Lipsky, M. (1980) Street Level Bureaucracy (New York: Russell Sage Foundation).

Lipsky, M. (2010) Street Level Bureaucracy, 30 ${ }^{\text {th }}$ Anniversary Edition (New York: Russell Sage Foundation).

Livingstone, S., L. Haddon, A. Görzig and K. Ólafsson (2011), 'EU Kids Online', London School of Media and Communications, UK, [Online].

http://www.Ise.ac.uk/media@Ise/research/EUKidsOnline (accessed 2 March 2014).

Livingstone, S., M. Bober and E. J. Helsper (2005), 'Active Participation or Just More 
Information?', Information, Communication and Society 8 3, 287-314.

Loader, B.D. (ed) (2007), Young Citizens in the Digital Age: Political Engagement, Young People and New Media (London: Routledge).

Lovink, G. (2011), Networks Without a Cause: A Critique of Social Media (Cambridge, UK: Polity Press).

Madden, M., A. Lenhart, M. Duggan, S. Cortesi and U. Gasser (2013), 'Teens and Technology', Pew Internet and American Life Project. Available: http://www.pewinternet.org/2013/03/13/teens-and-technology-2013/ (accessed 11 February 2014).

Margetts, H. (2009), 'Public Management Change and E-government: the Emergence of DigitalEra Governance', in A. Chadwick and P. Howard (eds) The Routledge Handbook of Internet Politics (Abingdon, Oxon: Routledge), 114-127.

McLoughlin, I. and J. Cornford (2006), 'Transformational Change in the Local State? Enacting E-Government in English Local Authorities', Journal of Management and Organization 12, 3, 195-208.

Metcalf, A., M. Blanchard, T. McCarthy and J. Burns (2008), 'Bridging the Digital Divide: Utilising Technology to Promote Social Connectedness and Civic Engagement amongst Marginalised Young People', 3C Journal of Community, Citizen's and Third Sector Media and Communication 4 8, 1-15.

Morrow, B. (2012), 'BYOD Security Challenges: Control and Protect your most Sensitive Data', Network Security 12, 5-8.

Nah, S. and G. D. Saxton (2013), Modeling the Adoption and use of Social Media by Nonprofit Organizations, New Media and Society 15, 294-313.

National Association of Schoolmasters Union of Women Teachers. (2013), Social Networking Guidelines for Members (London: NASUWT). Available:

http://www.teachers.org.uk/node/12516 (accessed 13 February 2015).

National Council for Voluntary Organisations. (2014), NCVO UK Civil Society Almanac (London: NCVO). Available: http://data.ncvo.org.uk/a/almanac12/how-are-public-sector-spending-cutsaffecting-the-voluntary-sector/ (accessed 14 February 2015).

National Union of Teachers. (2014), E-Safety: NUT Guidance and Model Policy (London: NUT). Available: http://www.teachers.org.uk/node/12516 (accessed 13 February 2015).

Office of the Deputy Prime Minister. (2005), Inclusion through Innovation: Tackling Social Exclusion through New Technologies (London: ODPM).

Office of National Statistics. (2014), Internet Access - Households and Individuals (London: ONS). Available: http://www.ons.gov.uk/ons/dcp171778_373584.pdf (accessed 1 March 2015).

Orlikowski, W. J. (1992), The Duality of Technology: Rethinking the Concept of Technology in Organizations, Organization Science 3 (3), 398-427

Orlikowski, W. J. (2000), Using Technology and Constituting Structures: A Practice Lens for Studying Technology in Organizations. Organization Science 11(4), 404-428.

http://dx.doi.org/10.1287/orsc.11.4.404.14600

Orlikowski, W. J. (2007), Sociomaterial Practices: Exploring Technology at Work, Organization Studies 28 (09), 1435-1448, DOI: 10.1177/0170840607081138

Pickard, J. (2014), 'Britain and the Cuts: Councils Set Aside £2.3bn as Austerity Hits”, Financial Times, 10.11.14. Available: http://www.ft.com/cms/s/0/4f7b0bae-34f7-11e4-ba5d00144feabdc0.html\#axzz3SYRZaLE2 (Accessed 14 January 2015).

Punie, Y., G. Misuraca and D. Osimo (eds) (2009), 'Public Service 2.0: The Impact of Social Computing on Public Services', [Online]. 
http://ipts.jrc.ec.europa.eu/publications/pub.cfm?id=2820 (accessed October 2013). Prensky, M. (2001), 'Digital Natives and Digital Immigrants', On the Horizon 9 5, 1-6. Qualman, E. (2012), Socialnomics: How Social Media Transforms the Way We Live and Do Business (New York, NY: Wiley).

Rainie, L. and B. Wellman (2012), Networked: The New Social Operating System (Cambridge, MA: MIT Press).

Reamer, F.G. (2013). 'Social Work in a Digital Age: Ethical and Risk Management Challenges', Social Work 58 2, 163-172.

Richardson, R. and A. Abbott (2013), The Role of Social Intermediaries in Digital Inclusion: The Case of Social Housing, CURDS Research Report RR2013/10 (Newcastle upon Tyne: Newcastle University). Available: http://www.ncl.ac.uk/curds/publications/reports.htm (accessed 22 February 2014).

Royal College of Nursing. (2012), RCN Guidance: Nursing Staff Using Personal Mobile Phones for Work Purposes (London: RCN).

Scott, S. and Wanda, V. and Orlikowski, J. (2014). "Entanglements in Practice: Performing Anonymity Through Social Media. MIS Quarterly 38 (3), 873-893.

Sercombe, H. (2010), Youth Work Ethics (London: Sage).

Slee, D. (2014), 'The Social Media Innovations Local Councils will Pioneer in 2014', The Guardian, 04.01.14. Available: http://www.theguardian.com/local-governmentnetwork/2014/jan/04/social-media-innovations-local-councils-2014 (accessed 4 January 2014).

Slee, D. and D. Caveney (2013), A White Paper on Social Media in Local Government (London: Local Government Information Unit). Available: http://www.lgiu.org.uk/briefing/a-white-paperon-social-media-in-local-government/ (accessed 19 February 2014).

Silcock, R. (2001), 'What Is E-Government?', Parliamentary Affairs 54, 1, 88-102.

Silverman, M., E. Bakhshalian and L. Hillman (2013), Social Media and Employee Voice: the Current Landscape (London: Chartered Institute of Personnel and Development). Available: http://www.cipd.co.uk/hr-resources/research/social-media-employee-voice.aspx (accessed 14 January 2014).

Spielhofer, T. (2010), Children's Online Risks and Safety: A Review of the Available Evidence. London: UK Council for Children Internet Safety, http://www.nfer.ac.uk/publications/COJ01/COJ01.pdf (accessed December 2013).

Stevenson, L. (2014), 'HCPC Sanctions Social Worker Over Facebook Posts', 10.09.14. Available: http://www.communitycare.co.uk/2014/09/10/social-worker-given-conditionspractice-order-disrespectful-facebook-posts/ (accessed 3 November 2014).

Strom, P.S. and R. D. Strom (2009), Adolescents in the Internet Age (Charlotte, N.C: Infopage). Tapscott, D. (2009), Grown Up Digital: How the Net Generation is Changing Your World (New York, NY: McGraw-Hill).

Tapscott, D. and A. D. Williams (2006), Wikinomics: How Mass Collaboration Changes Everything (New York, NY: Penguin).

Thomson, G. (2012), 'BYOD: Enabling the Chaos', Network Security 22, 2, 5-8.

Thornton, J. (2014), Local Government in the Digital Age (London: Local Government Association). Available: http://www.local.gov.uk/health-and-well-being-research//journal_content/56/10180/6035646 (accessed 20 November 2014).

United Nations. (2014), 'UN E-Government Survey', http://unpan3.un.org/egovkb/enus/Reports/UN-E-Government-Survey-2014 (accessed 1 September 2014).

Wallace, P. (2014), The Internet in the Workplace: How New Technology is Changing Work (New York, NY: Cambridge University Press). 
Young Foundation. (2010), Listen, Participate, Transform: A Social Media Framework for Local Government (London: Young Foundation). Available:

http://youngfoundation.org/publications/listen-participate-transform-a-social-media-frameworkfor-local-government/ (accessed October 2013).

\section{Footnote}

${ }^{1}$ Published by the Department for Communities and Local Government, the Indices of Multiple Deprivation (IMD) is a weighted indicator of poverty across criterion including income, employment, health, education, housing, services, crime and environment. 